\title{
Violencia contra periodistas e impunidad ${ }^{*}$
}

\author{
José C. Ugaz Sánchez-Moreno**
}

\section{Introducción y objetivos}

En los últimos años se ha venido percibiendo una creciente tendencia en América Latina expresada en la violencia ejercida contra periodistas como consecuencia del ejercicio libre de su profesión.

Dada la debilidad institucional que caracteriza a la mayoría de países de América Latina, especialmente a las instituciones vinculadas al quehacer de la justicia, el periodismo independiente, y en particular el periodismo de investigación, ha cobrado un papel muy relevante en materia de denuncia y fiscalización. Esto ha determinado que diversos grupos de poder o personajes aludidos por la prensa, reaccionen ejerciendo violencia contra los periodistas, ya sea para evitar ser objeto de información, para disuadir a otros o simplemente como represalia.

Son muchos los casos de este tipo en la región que pueden ser citados ${ }^{1}$. Este fenómeno, que antes podía ser identificado con las dictaduras que asolaron el subcontinente, hoy se presenta en la mayoría de países latinoamericanos, y no existen mayores diferencias entre aquellos gobernados por regímenes autoritarios y los que lo son por gobiernos democráticos.

* Este artículo se entregó como documento de trabajo para el proyecto sobre violencia contra periodistas e impunidad del Diálogo Interamericano.

** Profesor principal de la Facultad de Derecho de la Pontificia Universidad Católica del Perú.

1 El asesinato del periodista José Luis Cabezas en Argentina, los homicidios de Jaime Garzón, Orlando Sierra y Guillermo Bravo en Colombia, de Germán Rivas en Honduras y los casos emblemáticos de Miguel Pérez Julca, Antonio de la Torre y Alberto Rivera en el Perú, son algunos de los ejemplos de agresión a hombres de prensa ocurridos en los últimos años. 
Según la Red de Periodistas en Emergencia del Instituto Prensa y Sociedad (IPYS), el número de periodistas agredidos en el Perú a nivel nacional subió de 23 en 2003 a 64 en 2006, es decir prácticamente se triplicó ${ }^{2}$.

De otro lado, en materia de agresiones, no parece haber diferencia en función al tipo de medio de comunicación en que trabaja la víctima. De acuerdo al IPYS, de los periodistas amenazados en el Perú en el año 2006, 18 trabajaban en radio, 17 en televisión y 16 en prensa escrita.

Existen diversos grados de presión que pueden ser aplicados a la prensa a fin de obstaculizar su trabajo, amenazarla, censurarla ${ }^{3}$ o simplemente vengarse $^{4}$. Desde la imposición de sobrecostos a los insumos de trabajo o manipulación de las licencias necesarias para informar, hasta los más graves, consistentes en la agresión física, desaparición forzada o asesinato. Para efectos de este trabajo, interesan las acciones de violencia con relevancia legal, es decir aquellos casos en los que la agresión a periodistas constituye delito y por ende deben ser materia de una sanción penal.

De otro lado, resulta sintomático que el desarrollo creciente de la violencia contra periodistas, se presente acompañado de otro fenómeno igualmente preocupante: la impunidad para los perpetradores de estos actos de violencia. En efecto, tratándose de crímenes alevosos y usualmente notorios dada la relevancia social de las víctimas, llama la atención la poca efectividad demostrada por las instituciones del sistema de justicia encargadas de investigar y sancionar estos actos (policía, Fiscalía, Poder Judicial). Se advierte con frecuencia en estos casos una tendencia a la inacción por parte de las agencias del sistema de justicia, mientras que en otros, simplemente una falta de efectividad en los resultados, que sobresale respecto de los índices regulares que caracterizan al sistema penal en general para otros delitos en los que las víctimas no son periodistas agredidos como consecuencia del ejercicio de su profesión.

2 El concepto de agresión empleado por el IPYS incluye agresión física, amenazas, procesos judiciales, detenciones, querellas, incautación de equipos, impedimento de la labor periodística, reglaje, intento de asesinato y asesinato.

3 Ya sea de forma directa o indirecta, aunque una de las consecuencias más frecuentes de la violencia ejercida sobre el periodismo es la autocensura que se imponen los informadores como estrategia de sobrevivencia.

4 En el Perú, en el año 2006, hubo 20 agresiones físicas contra periodistas y 11 amenazas de muerte (IPYS). 
Desde esa perspectiva, interesa determinar cuál es la relación entre violencia contra periodistas e impunidad, es decir si los delitos contra periodistas son sancionados en menor grado que el resto de delitos en los que no aparecen involucrados estos profesionales, o si por el contrario comparten el mismo destino que el resto de conflictos penales.

Una variable que puede explicar esta problemática, tiene que ver con la característica de los agresores. Partimos del supuesto que la prensa independiente - y en particular la prensa de investigación - suele ser incómoda para grupos de poder de diversa naturaleza: grupos de poder político a los que afecta ser cuestionados o puestos en evidencia ante la opinión pública, funcionarios públicos en el poder, grupos de poder económico incursos en actividades ilegales, organizaciones o redes criminales, etcétera. En el ámbito regional, puede tratarse de personajes individuales afincados en el poder local — legal o ilegal — a quienes la actividad informativa incomoda al poner en cuestión su posición predominante .

Igualmente es necesario indagar qué ocurre con los operadores del sistema penal en estos casos y por qué la poca efectividad en la investigación y sanción de estos delitos. Para ello habrá que establecer si la mayor o menor independencia y la forma en la cual están organizadas las agencias del sistema criminal juegan un papel en la forma como son procesados estos casos.

Dada la tendencia latinoamericana a pretender resolver los problemas de la realidad a través de la ley, es pertinente establecer si la impunidad de la que gozan los crímenes contra periodistas en la región obedece a una deficiencia legislativa o si, por el contrario, pese a que existen suficientes leyes y adecuada protección normativa, estamos frente a un problema de aplicación de la ley, ajeno a la estructura legal.

Se ha elegido circunscribir esta investigación a lo ocurrido en la materia en México y Colombia, dado que la violencia contra periodistas, pero sobretodo la impunidad que rodea estos casos, ubica a ambos países como los más caracterizados de la región ${ }^{6}$.

5 Según el IPYS, en el año 2005, las agresiones contra periodistas peruanos provinieron de diversos sectores: desconocidos (13), Poder Judicial (8), turba de protestantes (5), personal de seguridad (5), policía (3), comunidades campesinas (4), empresarios (3), familiares (3), Fiscalía (2), funcionarios (6) y sindicatos (2).

6 De acuerdo con un reciente documento de trabajo del IPYS, «México se ha convertido en el país más peligroso para ejercer la actividad informativa en América Latina, 


\section{Legislación adecuada}

En materia de legislación, un elemento común a ambas naciones, es que desde el punto de vista formal, las normas jurídicas existentes en materia de derechos fundamentales, libertad de expresión, debido proceso legal y sanciones penales, parecen suficientes para garantizar el libre ejercicio del periodismo y la investigación y represión de aquellos que atenten contra este y contra la integridad de los informadores.

En el caso de México, el artículo 6 de la Constitución consagra el derecho a la libertad de expresión del pensamiento y señala que el Estado garantiza el derecho a la información, aun cuando los límites al ejercicio de este derecho (ataques a la moral, a derechos de terceros, perturbación del orden público o comisión de algún delito), admiten interpretaciones extensivas que por su subjetividad pueden dar lugar a restricciones indebidas. Recientemente, mediante Decreto Presidencial del 13 de junio del presente año, que complementa el artículo 6 constitucional, se adicionaron 8 principios que complementan la protección al derecho a la libertad de expresión 7 . Por su parte el artículo 7 del mismo cuerpo de leyes consagra la inviolabilidad de este derecho, la prohibición de la censura previa, así como la libertad de imprenta.

Por su parte, el artículo 2 de la Constitución de Colombia desarrolla una declaración inequívoca de reconocimiento y respeto a la libertad de expresión y de prensa ${ }^{8}$.

Ambos países adoptan las nociones modernas de debido proceso y han suscrito los instrumentos internacionales más importantes en materia de libertad de expresión, derechos humanos y acceso a la información, como

principalmente por la acción del narcotráfico». Por otro lado, según el Comité para la Protección de Periodistas (CPJ), Colombia está ubicada entre los 5 primeros países más peligrosos del mundo para el ejercicio del periodismo; en el período comprendido entre 1986 y 2006, han sido asesinados 54 periodistas. El último asesinato ha ocurrido mientras escribíamos este informe. El 21 de octubre de 2007 fue victimado el reportero gráfico Carlos Alberto Jaramillo al norte de la ciudad de Cali.

7 Publicidad, protección de la vida privada y datos personales, acceso a la información y preservación de archivos.

8 Se garantiza a toda persona la libertad de expresar y difundir su pensamiento y opiniones, la de informar y recibir información veraz e imparcial, y la de fundar medios masivos de comunicación. Estos son libres y tienen responsabilidad social. Se garantiza el derecho a la rectificación en condiciones de equidad. No habrá censura. 
la Convención Interamericana de Derechos Humanos y el Pacto Internacional de Derechos Civiles y Políticos.

\section{Marco institucional}

Desde el punto de vista de la existencia de instituciones que aseguren la vigencia de los derechos reconocidos en la letra de la ley, esta investigación revela que tanto México como Colombia, con las particularidades que implica una organización federal en el caso del primero, cuentan con los organismos básicos para cumplir adecuadamente con dicho propósito.

En ambos casos, existe la institución del Ombudsman (Comisión Nacional de Derechos Humanos en México y Procurador de Derechos Humanos en Colombia). En México la CNDH desarrolló un Programa Especial de Periodistas, que luego de ser ampliado y reorganizado, derivó en el Programa de Agravios a Periodistas y Defensores Civiles de Derechos Humanos, en virtud del cual se recomienda a las autoridades la investigación de estos casos. De los 30 expedientes abiertos que mantiene la Comisión, 12 están siendo procesados ante la Subprocuraduría de Investigación Especializada en Delincuencia Organizada (SIEDO), uno ante la Fiscalía Especial para la Atención de Delitos contra Periodistas (FEADP) y 17 ante las procuradurías de los Estados, las que son autónomas.

En el ámbito del Poder Ejecutivo mexicano, la Procuraduría General de la República (equivalente a la Fiscalía de la Nación o Ministerio Público en otros países), si bien no goza de autonomía funcional como sería deseable, ha desarrollado lineamientos que deberán seguir sus delegados estatales para la atención de los delitos cometidos contra periodistas. Incluso se ha creado la Fiscalía Especial para la Atención de Delitos cometidos contra Periodistas. Lamentablemente, esta Fiscalía carece de las facultades y competencia necesarias para lograr sus objetivos?.

De otro lado, pese a ser la institución creada exclusivamente para atender estos delitos, parece competir con otras instancias de la misma Procuraduría en el conocimiento de los casos, viéndose desplazada en la práctica

9 No incide directamente en la conformación de los expedientes y por tanto interviene en las investigaciones como coadyuvante, en un papel semejante al del ombudsman no jurisdiccional. 
de participar en la mayoría de ellos. De los 168 casos reconocidos por la FEADP como delitos contra periodistas en el fuero federal, solo ha podido conocer 56, pues el resto fueron asumidos por otras instancias de la PGR como la Secretaria de Control Regional, Procedimientos Penales y Amparo (SCRPPA) — 90 casos—, la Subprocuraduría Investigadora Especializada en Delincuencia Organizada (SIEDO) - 21 casos - y la Visitaduría General (un caso). A ello se suma que no cuenta con los recursos humanos y financieros, indispensables para atender las graves amenazas a la libertad de expresión que constituyen los asesinatos, agresiones y amenazas contra periodistas y medios de comunicación ${ }^{10}$.

De los 54 casos conocidos por la FEADP, solo 32 han tenido algún tipo de resolución, pero de estos únicamente en seis se iniciaron investigaciones.

En Colombia, producto de un esfuerzo conjunto entre el gobierno y la sociedad civil, se ha creado el Programa de Protección de Periodistas del Ministerio de Interior y Justicia ${ }^{11}$, el mismo que en los primeros siete ańos de existencia, ha atendido a 670 periodistas, dos de los cuales fueron asesinados ${ }^{12}$.

Para la implementación del programa se creó el Comité de Reglamentación y Evaluación de Riesgos (CRER), de composición plural (representantes del gobierno, agencias de control y organizaciones de derechos humanos y periodismo). La Fundación para la Libertad de Prensa es la encargada de recoger y documentar los casos de violaciones a la libertad de prensa y sugiere las medidas a adoptar en cada caso, las que pueden ser clasificadas en:

Medidas duras

- Esquemas móviles de protección: con vehículos propios o alquilados, con apoyo de transporte, escoltas, medios de comunicación, armas, chalecos antibalas, individuales o colectivos.

- Blindajes arquitectónicos: es la dotación de equipos de seguridad integral para el control perimetral de la sede de una organización.

- Blindajes a vehículos: es la instalación de blindaje a vehículos de las entidades territoriales.

10 El presupuesto asignado no ha aumentado desde su creación mientras que la Subprocuraduría de Derechos Humanos, Atención a Víctimas y Servicios a la Comunidad, de la cual depende, ha sufrido un recorte presupuestal del $50 \%$.

11 Ley 418 de 1977 y Decreto 1542 de 2000.

12 Los periodistas José Rivas y Luis Eduardo Alfonso. 
- Tiquetes internacionales: medida de protección excepcional, para que el beneficiario de la misma, salga a otro país y permanezca temporal o definitivamente allí.

Medidas blandas

- Equipos de comunicación.

- Medios de transporte: tiquetes nacionales o apoyo de transporte terrestre.

- Apoyo de reubicación temporal: constituye la asignación mensual de hasta tres salarios mínimos mensuales legales vigentes (SMMLV), ante la salida de la zona de riesgo, por un máximo de tres veces. De manera extraordinaria se podrá otorgar apoyo de reubicación temporal por tres veces adicionales, por la mitad del monto ordinario.

- Apoyo de trasteo: consiste en apoyar económicamente el traslado de los bienes muebles de la persona que ha decidido trasladarse temporal o definitivamente a una zona que le ofrezca mejores condiciones de seguridad.

Aunque la creación del programa ha significado un avance en materia de protección a periodistas, y a pesar de que cuenta con un procedimiento para atención de casos urgentes, se le critica que aún es muy lento en su capacidad de respuesta.

Igualmente se ha desarrollado un comité especial de policías e investigadores de la Fiscalía, quienes trabajan conjuntamente con la organización Colombia Foundation for Press Freedom, tienen por objetivo combatir la violencia y las amenazas contra los periodistas.

En cuanto al sistema penal, de gran importancia para la investigación y persecución de los delitos cometidos contra periodistas, a raíz de la reforma constitucional de 2002, Colombia está viviendo un momento transicional por el paso de un sistema inquisitivo a uno de corte acusatorio que profundiza las reformas de 1991, año en que se creó la Fiscalía General y la Oficina del Defensor Público. Si bien un sistema acusatorio se considera más eficaz y garantista, y por lo tanto más adecuado para solucionar satisfactoriamente los conflictos penales, todo indica que a pesar de los avances logrados en Colombia, hasta la fecha persisten algunos problemas serios como la ineficacia de la investigación 
administrativo-policial y la morosidad para resolver los casos. Estos problemas han determinado altos niveles de impunidad que algunos analistas estiman que alcanzan hasta un $80 \%$ de los casos aproximadamente ${ }^{13}$.

El sistema penal en México está marcado por la distinción entre lo federal y lo estadual, lo que determina la existencia de dos catálogos de delitos, así como reglas de competencia entre las autoridades judiciales de ambos niveles, que establecen que cuando existe conexión entre infracciones penales locales y federales, corresponde a la autoridad federal — reservada para los delitos más graves - conocerlas. Sin embargo, al existir una instancia especializada en conocer los delitos cometidos por la delincuencia organizada (SIEDO), es usual el cruce de competencias, habiendo asumido esta hasta un $20 \%$ de los homicidios contra comunicadores sociales. A ello se agrega que la mayoría de los casos no se tramitan en la justicia federal, sino en el ámbito local, debido a exigencias formales como la acreditación de la calidad de periodista de la víctima o a que se les califica como delitos del fuero común y no del federal. Atendiendo a las reglas de conexión entre ambas jurisdicciones, usualmente las primeras investigaciones se realizan a nivel local, lo que limita o perjudica su desarrollo posterior.

\section{Violencia contra periodistas e impunidad}

Entre los años 2000 y 2006, se registraron en México 27 asesinatos de periodistas y cinco desapariciones, siendo la tendencia claramente ascendente, al punto que en el período 2004-2006, el número de homicidios prácticamente se triplicó respecto del trienio anterior $(7 v s .20$, respectivamente), al punto que, de los 20 asesinatos ocurridos entre 2004 y 2006, 10 (50\%) se produjeron en 2006. A ello se agrega que existen muchas otras formas de presión menos violentas que han llegado a sumar 526 hasta abril de 2006, incluyendo la detención de 34 hombres de prensa.

En la mayoría de los casos acaecidos en México, existen indicios razonables y suficientes para asumir que los crímenes fatales están relacionados con el crimen organizado y/o el narcotráfico, y que el móvil fundamental sea silenciar las publicaciones informativas relacionadas con estas actividades

13 Cfr. informe de Brian Treacy para este proyecto «Impunidad en casos de delitos contra periodistas: El caso Colombia», setiembre 2007, p. 5. 
ilícitas. Se ha logrado determinar que en un $42 \%$ de los asesinatos, los perpetradores son agentes del Estado - lo que por otro lado evidencia el nivel de infiltración de las organizaciones criminales en el Estado mexicano-, proviniendo la mayoría de estos de la policía (24\%), con lo que ocurre que la institución que debe investigar inicialmente las agresiones, contradictoriamente cobija a los agresores.

Pese a la gravedad de los delitos, únicamente once casos han pasado a la justicia federal, caracterizándose la mayoría de las investigaciones por ser deficientes y endebles, sin evidenciar avances significativos.

La impunidad es una constante en este tipo de crímenes en México, pero la falta de investigación y sanción penal a los autores parece ser un problema que no se circunscribe a los crímenes contra periodistas sino a los delitos en general, producto de las deficiencias estructurales del sistema judicial mexicano. De otro lado, en lo que atańe a los homicidios de periodistas, se observa adicionalmente poca voluntad política para impulsar las investigaciones, lo que se traduce en las limitaciones impuestas a la FEADP y en la falta de coordinación de esta con la $\mathrm{CNDH}$, lo que algunos atribuyen a su sometimiento a los intereses de los sectores involucrados.

En cuanto a Colombia, según las fuentes consultadas, entre 1993 y 2006, 107 periodistas fueron asesinados. Conforme a reportes del Relator Especial de Libertad de Expresión de la OEA, entre 1998 y 2005, existen 31 casos de periodistas asesinados por razones vinculadas al ejercicio de su profesión, de los cuales solamente seis han llegado a la fase de juicio, lo que implicaría que en el $80 \%$ de los casos, las investigaciones se han archivado o detenido por falta de evidencias, y no existe un solo caso en el que se haya condenado a los autores de estos crímenes. En cuanto a medios de presión contra informadores, la Relatoría ha reportado 99 denuncias para el período 1999-2005, aunque el Ministerio de Interior y Justicia ha registrado una cifra mucho mayor para ese mismo período (447). En lo que va del presente año, se han reportado 98 hechos delictivos que afectan a 180 periodistas.

Inversamente a lo que está ocurriendo en México, en Colombia se nota una tendencia a la baja en materia de asesinatos a periodistas por razones de su trabajo, pero por otro lado se advierte un incremento de las amenazas y otros medios de presión que están obligando a los informadores a abandonar su actividad, desplazarse o, en casos extremos, buscar el exilio. 


\section{COLOMBIA}

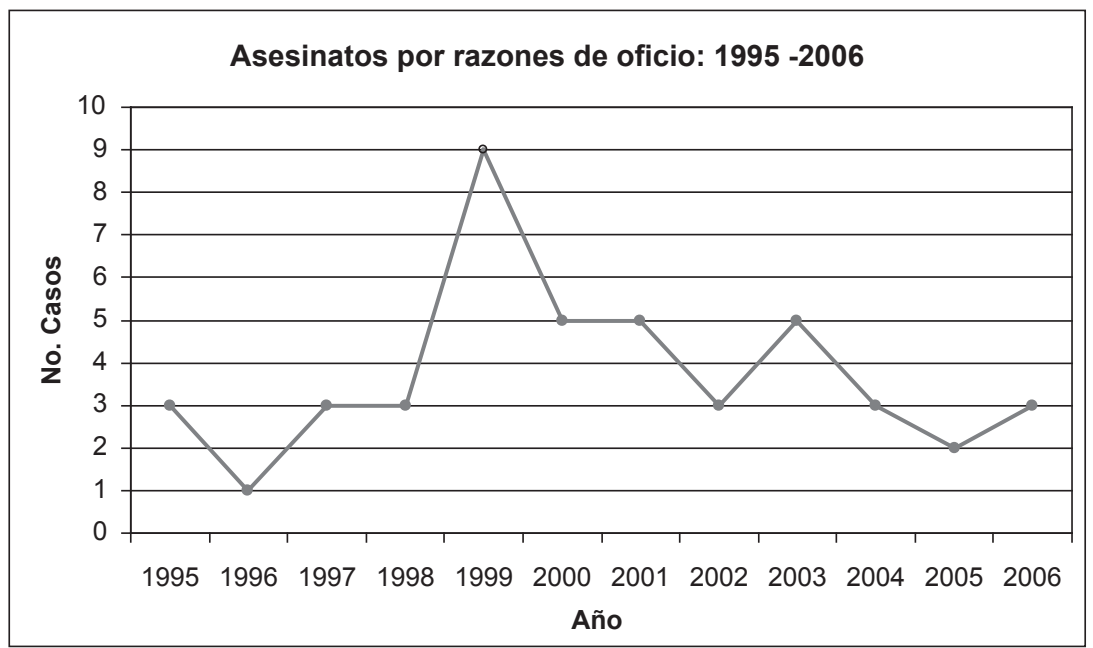

Todo indica que la reducción de los asesinatos obedece a que las amenazas estarían logrando el objetivo deseado de intimidar a los periodistas para que dejen de informar sobre determinados hechos (autocensura), y en consecuencia resulta innecesario escalar a un nivel de agresión mayor.

El mayor número de agresiones en la realidad colombiana proviene de los grupos paramilitares, los que en muchos casos precisamente arremeten contra los comunicadores sociales para evitar que se revelen sus vínculos con actores de la política, entre ellos diversos funcionarios locales y parlamentarios.

\section{COLOMBIA}

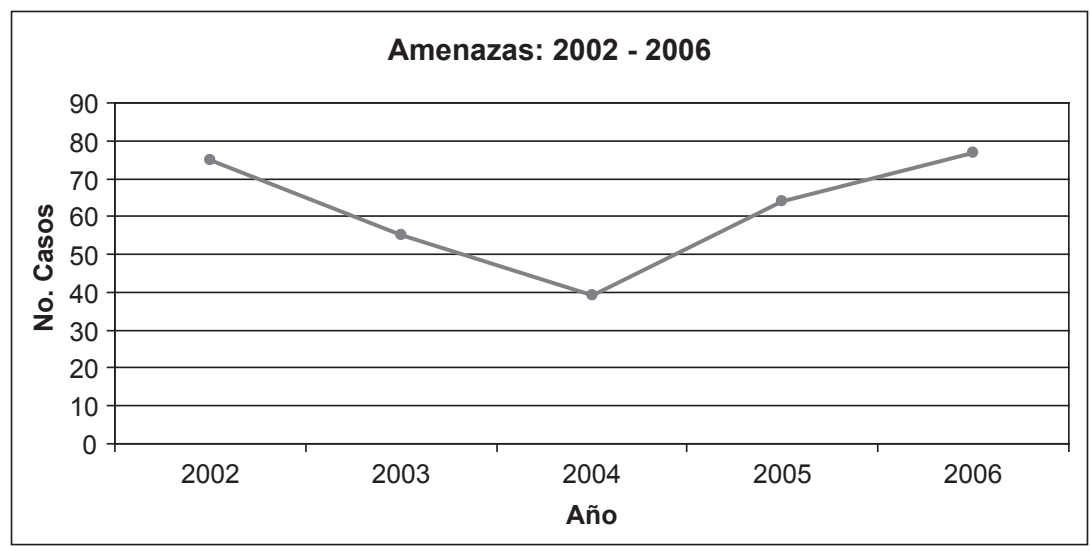


Al igual que lo ocurrido en México, se estima que en Colombia las cifras de impunidad para delitos de asesinato contra periodistas son muy altas y que las investigaciones no prosperan. Más que a una política de encubrimiento o a actos de corrupción de la justicia, todo indica que la falta de resultados obedece a la incapacidad y a la carencia de medios de los organismos encargados de investigar, como a la negligencia burocrática de los operadores del sistema penal.

Existe consenso al señalar que la consecuencia principal generada por las agresiones contra periodistas y la falta de sanción a los autores de estos hechos en ambos países es la autocensura, en virtud de la cual los comunicadores víctimas de la violencia se abstienen de informar sobre hechos que puedan poner en riesgo su integridad personal.

\section{Conclusiones}

1. Tanto en México como en Colombia, existen marcos legales suficientes en materia de reconocimiento y protección de los derechos fundamentales, entre ellos el derecho a la libertad de expresión y a las garantías del debido proceso legal. Por lo tanto, aun cuando ambos sistemas legales son perfectibles, el problema de la impunidad de los crímenes contra periodistas no obedece a una inadecuada regulación legislativa.

2. En ambos países, además de las instituciones propias del sistema penal (policía, Fiscalía y Poder Judicial) y de las oficinas del Ombudsman, se han creado programas especiales para documentar y proteger a los periodistas víctimas de agresiones (FEADP en México y Programa de Protección de Periodistas del Ministerio de Interior y Justicia en Colombia). Sin embargo, en ninguno de los dos casos estos programas han logrado resolver el problema de la impunidad en esta materia.

3. No basta crear instituciones o programas especiales para investigar estos casos si no se dota a las instituciones encargadas de su desarrollo de capacidad funcional, autonomía y recursos suficientes. En el caso de México, la Procuraduría General de la República, de la que depende la FEADP, es un órgano del Poder Ejecutivo, por lo que resulta un contrasentido que, siendo los principales autores de agresiones a periodistas agentes del Estado, se pretenda que esta sea la responsable de investigar y perseguir 
esos hechos. Como ocurre en la gran mayoría de países de la región, debe dotarse al Ministerio Público de autonomía constitucional.

De otro lado, se ha constatado que en ambos países, pese a la creación de organismos especializados, existe dispersión en el tratamiento de los casos, toda vez que los mismos son derivados o asumidos por instancias distintas a ellos.

4. La impunidad en materia de agresiones a periodistas es una realidad en los dos países investigados. Si bien esta problemática obedece en general a deficiencias estructurales de la justicia penal que afecta a la persecución de los delitos en general, parece agudizarse en estos casos debido a la falta de voluntad política para crear las condiciones que permitan investigaciones eficaces y oportunas.

\section{Recomendaciones}

1. Atendiendo a las carencias del sistema penal, es recomendable que este tipo de delitos se procesen en jurisdicción concentrada. En tal sentido, debería crearse un subsistema especializado en lo judicial y fiscal que conozca en exclusividad de los crímenes contra periodistas a nivel nacional (federal en el caso mexicano). Este subsistema debería ser integrado por un grupo reducido de magistrados y fiscales jóvenes, altamente motivados, capacitados y que gocen de la independencia funcional necesaria para poder investigar los casos a fondo, quienes deben contar con un equipo élite de investigadores policiales que dependan directamente de ellos y no de su comando policial. La competencia para conocer de estos casos debería determinarse por la calidad del agraviado sin formalismo alguno (por ejemplo, sin exigir que la víctima posea título profesional o colegiación), invirtiendo la lógica actual: si se presume que es periodista, se procesa el caso en el subsistema especializado, y si en el transcurso de la investigación resulta que no lo era, se le deriva al sistema ordinario.

A los jueces, fiscales y policías integrantes de este subsistema debe brindárseles entrenamiento técnico especializado en materia de investigación criminal, para lo cual se puede recurrir a la cooperación internacional de países con experiencia en la materia. 
2. Dado que los defensores cumplen un papel muy importante en el impulso de los procesos penales, debe crearse un sistema de defensores públicos para estos casos. En su defecto, las organizaciones no gubernamentales deben generar las condiciones para proveer de defensa idónea en aquellos casos en los que la parte agraviada no puede hacerlo.

3. Existiendo un componente de falta de voluntad política por la naturaleza de estos delitos, en los que se pretende silenciar a informadores incómodos para grupos de poder, es indispensable el monitoreo externo de los procesos. En tal sentido, se sugiere crear las condiciones legales para que organizaciones no gubernamentales especializadas en estos temas puedan incorporarse a los procesos penales como parte procesal coadyuvante. Mientras se crean esas condiciones, y en tanto no puedan actuar procesalmente, dichas organizaciones deben fiscalizar el desarrollo de las investigaciones y presentar sus resultados periódicamente a la opinión pública, sin descartar la posibilidad de llevar los casos de impunidad local al Sistema Interamericano de Derechos Humanos.

Igualmente estas organizaciones especializadas deben contribuir a dotar de elementos técnicos de juicio a los operadores legales, para lo cual se sugiere adoptar como una estrategia de la sociedad civil, la incorporación de informes amicus curiae a las investigaciones por delitos contra periodistas.

4. Es aconsejable involucrar a actores internacionales en la solución de esta problemática. Debe pedirse a la Relatoría Especial para la Libertad de Expresión de la OEA, una evaluación de la idoneidad de los programas mexicano y colombiano establecidos para la investigación de estos casos a fin de determinar los ajustes necesarios, especialmente en lo que respecta a la autonomía funcional de los operadores legales y la asignación de recursos.

En ambos casos debería haber visitas in loco anuales de la Relatoría a fin de sensibilizar a las autoridades y urgirlas a actuar a partir de las evaluaciones sobre impunidad en esta materia, e incluir el tema en las sesiones periódicas de la Comisión Interamericana buscando generar instancias de presión al interior de la OEA. 
5. Se debe establecer la obligación legal de que los responsables de la Fiscalía y/o el Poder Judicial rindan cuentas, cuando menos una vez al año, del resultado de las investigaciones y sus avances ante alguna comisión especializada del Congreso de la República.

6. En el ámbito preventivo, debe alentarse la creación en México de un programa de protección de periodistas similar al colombiano. En Colombia dicha experiencia debe ser evaluada por una misión técnica internacional a fin de corregir los defectos que la hacen lenta e ineficaz en algunos casos, debiendo incluirse un procedimiento abreviado y expeditivo para los casos de alerta por riesgo inminente.

7. Las oficinas defensoriales (Ombudsman), deberían tener un rol más activo en la fiscalización de las autoridades que procesan estos casos e intervenir en las investigaciones siempre que las leyes lo permitan. De no poder hacerlo, deben proveer a las autoridades con informes técnicos que contribuyan al avance de las investigaciones. 